\title{
A Rare Case of Intramural Müllerian Adenosarcoma Arising from Adenomyosis of the Uterus
}

Sun-Jae Lee · Ji Y. Park

Department of Pathology, Catholic University of Daegu School of Medicine, Daegu, Korea

Received: May 29, 2017

Revised: June 7, 2017

Accepted: June 11, 2017

\section{Corresponding Author}

Sun-Jae Lee, MD, PhD

Department of Pathology, Catholic University of

Daegu School of Medicine, 33 Duryugongwon-ro

17-gil, Nam-gu, Daegu 42472, Korea

Tel: +82-53-650-4629

Fax: +82-53-650-4834

E-mail: pathosjlee@cu.ac.kr

\begin{abstract}
Müllerian adenosarcomas usually arise as polypoid masses in the endometrium of post-menopausal women. Occasionally, these tumors arise in the cervix, vagina, broad and round ligaments, ovaries and rarely in extragenital sites; these cases are generally associated with endometriosis. We experienced a rare case of extraendometrial, intramural adenosarcoma arising in a patient with adenomyosis. A 40-year-old woman presented with sudden-onset suprapubic pain. The imaging findings suggested leiomyoma with cystic degeneration in the uterine fundus. An ill-defined ovoid tumor with hemorrhagic degeneration, measuring $7.5 \mathrm{~cm}$ in diameter, was detected. The microscopic findings showed glandular cells without atypia and a sarcomatous component with pleomorphism and high mitotic rates. There was no evidence of endometrial origin. To recognize that adenosarcoma can, although rarely, arise from adenomyosis is important to avoid overstaging and inappropriate treatment.
\end{abstract}

Key Words: Uterus; Müllerian adenosarcoma; Adenomyosis
Müllerian adenosarcoma is a relatively uncommon variant of Müllerian mixed tumor with distinctive clinical and histologic characteristics. ${ }^{1}$ The term Müllerian adenosarcoma was first used in 1974 to describe an unusual variant of Müllerian mixed tumor of the uterus, characterized by a mixture of benign or occasionally mildly atypical glandular components and malignant, usually low-grade, stromal components. ${ }^{2}$ The morphologic features of these neoplasms distinguish them from other biphasic (epithelial and mesenchymal) tumors, both benign and malignant. ${ }^{1}$ Müllerian adenosarcoma is generally of low malignant potential, except when accompanied by sarcomatous overgrowth and myoinvasion. ${ }^{1}$ Patients with Müllerian adenosarcoma lacking these two histopathologic features have an excellent prognosis; ${ }^{1}$ these tumors may recur locally but only rarely metastasize. ${ }^{2}$

Müllerian adenosarcomas generally arise from the eutopic endometrium in the uterine corpus and grow as polypoid masses in post-menopausal women who present with abnormal vaginal bleeding. ${ }^{2,3}$ These neoplasms, however, may also arise in ectopic foci of endometriosis, such as the uterine cervix, vagina, broad and round ligaments, and ovaries or even at extragenital sites in rare cases. ${ }^{4,5}$ For example, among 41 previously reported Müllerian adenosarcomas, 29 (71\%) were extrauterine, ${ }^{6}$ with the sites including the ovaries, cervix, peritoneum, pelvis, gastrointestinal tract, bladder, perirectal tissue, rectovaginal septum, pouch of Douglas, and liver. ${ }^{7}$ Some studies have reported that adenosarcomas arising in extrauterine and extragenital area may be associated with more aggressive clinical behavior, probably due to an increasing tendency for peritoneal spread. ${ }^{2}$

Extraendometrial uterine adenosarcomas, that is, tumors originating from adenomyosis or an adenomyoma and not from the eutopic endometrium, are rare, with no specific staging guidelines for these tumors provided in the new International Federation of Gynecology and Obstetrics (FIGO) staging system of uterine sarcomas. ${ }^{8,9}$ In fact, only a few prior cases of primary adenosarcoma arising from adenomyosis have been reported in the English literature. ${ }^{2,5,8,10}$ The present report describes the clinical and pathologic findings of a rare case of extraendometrial, intramural adenosarcoma arising from adenomyosis without eutopic endometrial involvement in a 40-year-old woman and briefly reviews the literature describing the clinical and pathologic characteristics of adenosarcoma arising from adenomyosis.

Because this is a descriptive case report and literature review, institutional review board approval was waived and personal information of the patient was de-identified. 


\section{CASE REPORT}

A 40-year-old woman (gravida 2, para 2) presented in July 2015 with sudden-onset suprapubic pain and initial low back pain. Gynecologic examination detected a round soft fist-sized mass in the right fundic area accompanied by bloody vaginal discharge. Laboratory examination of serum tumor markers showed that the concentration of carbohydrate antigen (CA) 125 was markedly elevated $(5,000 \mathrm{IU} / \mathrm{mL}$; normal, $<16 \mathrm{IU} / \mathrm{mL})$, while the concentration of CA19-9 was slightly elevated (39 IU/mL; normal, < 37 IU/ $\mathrm{mL}$ ). In contrast, the serum concentrations of $\beta$-human chorionic gonadotropin $(1.34 \mathrm{mIU} / \mathrm{mL})$ and $\alpha$-fetoprotein $(0.90 \mathrm{ng} / \mathrm{mL})$ were within normal limits.

Pelvic ultrasonography showed an enlarged uterus with a $7 \mathrm{~cm}$ solid and cystic mass (Fig. 1A). T2-weighted magnetic resonance imaging (MRI) demonstrated an enlarged uterus with a mass, measuring $71 \times 59 \times 72 \mathrm{~mm}$ in size, arising from the uterine fundus (Fig. 1B). An exophytic multilocular cystic lesion, measuring 43 $\times 39 \times 31 \mathrm{~mm}$, was also present in the cranial portion of the mass. These findings suggested peripheral intramural leiomyoma with cystic degeneration and cranial rupture.

The patient underwent laparoscopically-assisted total vaginal hysterectomy without nodal dissection and without oophorectomy. Laparoscopic examination revealed a hemorrhagic friable mass arising from the uterine fundus. The tumor was attached to the bowel and omentum. There was no evidence of peritoneal endometriosis or other peritoneal lesions.

Gross examination showed that the uterus measured $14 \times 7.5 \times$ $5.5 \mathrm{~cm}$ in size and weighed $54 \mathrm{~g}$. The uterine fundus contained an ill-defined, rubbery ovoid tumor, measuring $7.5 \mathrm{~cm}$ in diameter, with hemorrhagic degeneration and rupture (Fig. 2A). The remaining endometrium and cervix were unremarkable. The cut surface of the lesion was tan-brown in color, multicystic and solid (Fig. 2B).

Microscopic examination revealed a biphasic tumor composed of both dilated glandular elements and abundant, hypercellular stromal elements (Fig. 3A, B). The tumor revealed expansile growth within the myometrium with extensive myometrial invasion and focal infiltration with expansile margins into the subserosa (Fig. 3C).

The glands were lined by benign endometrioid cells that were columnar or cuboidal in shape, with focal secretion (Fig. 3D). Some of these glands showed mild hyperplasia with rare mitosis (0-1/10 high power fields [HPFs]) of the lining; however, the glandular epithelium showed no indications of malignancy.

The benign endometrial glands were surrounded by hypercellular spindle cell proliferation, with cells growing in a fascicular pattern. The stromal cells showed mild to moderate focal atypia with occasional mitotic figures (Fig. 3D, E). The mitotic count was $5 / 10$ HPFs, which was higher than that of the glandular cells. Diffuse hemorrhagic necrosis was present at the center of the mass.

Immunohistochemical analysis, performed with appropriate controls, showed that both the glandular and stromal cells were positive for estrogen and progesterone receptors (Fig. 3F) and focally positive for TP53 in the tumor tissue (Fig. 3G). The stromal cells were immunohistochemically positive for $\mathrm{CD} 10$ (Fig. $3 \mathrm{H}$ ) and smooth muscle actin (Fig. 3I), and their Ki-67 proliferation index was mildly increased (Fig. 3J).

These microscopic findings suggested that the tumor was a mixed epithelial-stromal tumor consisting of glandular cells without atypia (benign endometrial hyperplasia) and sarcomatous stromal cells with mild pleomorphism and a high mitotic rate


Fig. 1. Radiologic findings. (A) Pelvic ultrasonography, showing an enlarged uterus with a 7-cm solid and cystic mass. (B) T2-weighted magnetic resonance imaging, showing an enlarged uterus with a mass, measuring $71 \times 59 \times 72 \mathrm{~mm}$, arising from the uterine fundus. 
(low-grade endometrial stromal sarcoma). There was no evidence of sarcomatous overgrowth, a heterologous (i.e., muscle, cartilage, bone) or sex-cord element, or lymphovascular invasion.

The endometrium was unremarkable and the background myometrium showed focal involvement of adenomyosis. There was no evidence of serosal endometriosis or other tumors intrinsic or extrinsic to the uterus. Although the specimen was submitted in a ruptured state, there was no distinct evidence of serosal involvement of the tumor. The adenosarcoma was limited to the myometrium and was not detected on the serosal surface.
Taken together, these histologic findings indicated a low-grade Müllerian adenosarcoma arising from adenomyosis.

The patient underwent follow-up evaluation 2 weeks after surgery. Further clinical workup included a whole body bone scan and positron emission tomography/computed tomography (PET-CT) scan. There was no evidence of regional or distant metastasis. One month later, the patient underwent an additional bilateral salpingooophorectomy, omental biopsy, and cul de sac washing cytology. There was no residual adenosarcoma in the specimen.

To date, regular follow-up evaluation has shown no evidence


Fig. 2. Macroscopic findings of the hysterectomy specimen. (A) View showing an ill-defined ovoid tumor, $7.5 \mathrm{~cm}$ in diameter, together with hemorrhagic degeneration in the uterine fundus. (B) View showing that the cut surface of the lesion was tan-brown in color, multicystic, and solid.

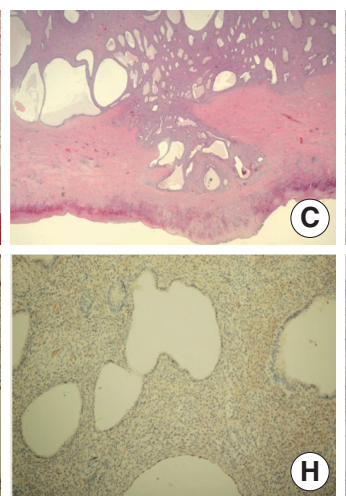


Fig. 3. Histologic and immunohistochemical findings. (A, B) Microscopic examination showing a biphasic tumor composed of both dilated glandular elements and abundant, hypercellular stromal elements. (C) The tumor shows expansile growth within the myometrium, with extensive myometrial invasion and focal infiltrates into the subserosa with expansile margins. (D) Proliferation of hypercellular spindle cells growing in a fascicular pattern, around benign endometrial glands. (E) The stromal cells show mild and focal moderate cytological atypia with occasional mitotic figures (arrows). (F-J) Immunohistochemical analysis showing that the glandular and stromal cells in tumor tissue are positive for estrogen receptor (F) and focally positive for p53 (G); that the stromal cells are positive for CD10 (H) and smooth muscle actin (I); and that the Ki-67 proliferation index is higher in the stromal component than in the epithelium (J). 
of tumor recurrence, with negative radiologic findings, including transvaginal ultrasonography, chest and pelvic computed tomogragphy, and whole body PET-CT. Her elevated serum CA125 level resolved immediately after surgery and has continued to remain in the normal range.

\section{DISCUSSION}

Uterine sarcomas of any type are rare when compared with uterine epithelial malignancies. Especially, Müllerian adenosarcomas are highly rare, accounting for only $3 \%-7 \%$ of all uterine sarcomas. ${ }^{11,12}$

Despite their rarity, these tumors affect women of all age groups. ${ }^{1}$ Although most adenosarcomas of the female genital tract occur in post-menopausal women (median age, 58 years), these tumors have been reported in perimenopausal women as well as in children as young as 10 years old. ${ }^{12}$ Clinically, the patients usually present with vaginal bleeding, but may also present with other nonspecific symptoms, such as pelvic pain and vaginal discharge; a large percentage of patients are asymptomatic. ${ }^{1,2}$

Although the eutopic endometrium of the uterus is the most common primary site, adenosarcomas may arise in the ovaries, fallopian tubes, cervix, or vagina, as well as at extragenital sites in rare cases. ${ }^{3}$ Adenosarcomas occurring outside the female genital tract likely represent tumors arising from preexisting endometriosis. ${ }^{5}$ In fact, approximately $1 \%-10 \%$ of these tumors are thought to arise from the malignant transformation of endometriosis. ${ }^{4}$ Endometrioid adenocarcinomas and clear cell carcinomas are the most common tumor types, occurring in $70 \%$ and $14 \%$ of patients, respectively. ${ }^{4}$ Only a limited number of stromal tumors including adenosarcoma have been reported to date. ${ }^{4}$

Furthermore, these tumors are thought to arise from the endometrial stroma, they can implant into the myometrium and coexist with diffuse adenomyosis or focal adenomyoma; however, only a few cases of intramural adenosarcoma arising from adenomyosis have previously been reported in the English literature. $2,5,8,10,13-15$ These include intramural adenosarcomas originating in the foci of adenomyosis, ${ }^{5}$ intramural adenomyoma, ${ }^{8}$ and deep subserosal adenomyoma ${ }^{2}$ with no evidence of eutopic endometrial origin. The detailed clinicopathologic characteristics of previously described patients are summarized in Table 1.

An essential feature of these adenosarcomas is their mixed nature, including both benign and neoplastic epithelial and malignant stromal elements. ${ }^{3}$ The epithelium, which may be dilated or slit-like in appearance, is mostly endometrioid type, usually composed of cuboidal or low columnar cells, although ciliated, mucinous, and occasionally squamous type epithelial cells have also been identified. ${ }^{3}$ Abundant eosinophilic cytoplasm may also be present in the epithelial cells. ${ }^{3}$ The epithelial cells are usually in active phase, showing mitoses or subnuclear vacuolation, in spite of the adjacent atrophic endometrium. ${ }^{3}$ Focal crowded glands with nuclear atypia may occur, which are indicators of atypical hyperplasia. ${ }^{3}$

The stromal component, which is usually low grade, is composed of spindle and/or round cells. ${ }^{3}$ In a minority of patients, including ours, the stromal component is uniformly cellular. ${ }^{3}$ The formation of a "periglandular cuffing" or "cambium" layer, in which the stroma surrounds the glandular elements, is one of the most characteristic features of adenosarcoma. ${ }^{3}$ This cellular zone is characterized by variable degrees of nuclear atypia and mitosis. ${ }^{3}$ Although most of these tumors have a mitotic count of $\geq 2 / 10$ HPFs, some tumors have a lower count. ${ }^{3}$ The World Health Organization criteria consider stromal mitotic activity $>1 / 10$ HPFs diagnostic of adenosarcoma, whereas other classification systems use a cutoff of $4 / 10$ HPFs. ${ }^{3}$ Moreover, many adenosarcomas include large areas of stromal fibrosis without mitotic activity. ${ }^{3}$ Stromal components of adenosarcomas are exclusively homologous, that are normally seen in the uterus. ${ }^{3}$ The most common mesenchymal elements consist of low-grade endometrial stromal or nonspecific fibroblastic components; the stromal cells in the periglandular area are often endometrial stromal type whereas that located away from the glands are typically of nonspecific fibrous type. ${ }^{3}$ Approximately one quarter of adenosarcomas show heterologous stromal components, comprising predominantly rhabdomyosarcoma; however, chondrosarcoma and liposarcoma may also be seen. ${ }^{16}$ Sex cord-like components, such as cords, solid nests, and/or hollow tubules, may be found within the stromal component. ${ }^{3}$ Occasionally, marked decidualization of the stroma may also be present, secondary to hormonal usage. ${ }^{3}$

Adenosarcoma is one of the mixed Müllerian tumors of the female genital tract, located between adenofibroma and carcinosarcoma (so called malignant mixed Müllerian tumor) on the spectrum. ${ }^{3}$ Because these tumors are rare, the precise molecular mechanism associated with their tumorigenesis is not fully understood. ${ }^{1}$ Some studies have reported low rates of TP53 mutations, and low-level amplification of MDM2 and other genes on chromosome band 12q14-15. ${ }^{17}$ Recently described alterations in adenosarcoma include MYBL1 amplification and ATRX mutation, each of which has been detected in $50 \%$ of adenosarcomas with sarcomatous overgrowth. ${ }^{17}$ Immunohistochemical analysis of the tumor in our patient showed an overexpression of TP53 in both epithelial and stromal cells. In a previous study, an adenosarcoma with sarcomatous overgrowth was found to have a hyperdiploid karyotype with multiple structural and numerical abnormalities involving 
Table 1. Clinicopathologic features of adenosarcomas arising from adenomyosis

\begin{tabular}{|c|c|c|c|c|c|}
\hline $\begin{array}{l}\text { Case No. } \\
\text { (ref No.) }\end{array}$ & Clinical feature & Pathology & Treatment & Outcome & Remarks \\
\hline \multirow[t]{4}{*}{$1^{15}$} & Age: $51 \mathrm{yr}$ & Size: $4 \mathrm{~cm}$ & Unknown & Unknown & - \\
\hline & Gyn hx: unknown & Location: lateral wall of the uterine body & & & \\
\hline & Clinical sign: unknown & $\begin{array}{l}\text { Micro: } \\
\text { Glands with no epithelial cell atypia } \\
\text { Sarcomatous component with cell pleomorphism } \\
\text { and a high mitotic count } \\
\text { Accompanied by adenomyosis }\end{array}$ & & & \\
\hline & Tumor marker: unknown & & & & \\
\hline \multirow[t]{4}{*}{$2^{13}$} & Age: $20 \mathrm{yr}$ & Size: unknown & Hysterectomy & $\begin{array}{l}\text { Two years } \\
\text { after surgery, } \\
\text { no evidence } \\
\text { of recurrent } \\
\text { disease }\end{array}$ & Stromal overgrowth \\
\hline & Gyn hx: null & Location: right anterolateral portion & & & \\
\hline & $\begin{array}{l}\text { Clinical sign: a long- } \\
\text { standing history of } \\
\text { menorrhagia and vaginal } \\
\text { bleeding }\end{array}$ & $\begin{array}{l}\text { Micro: } \\
\text { Florid adenomyosis with extensive myometrial } \\
\text { invasion, expansile growth within the } \\
\text { myometrium, and intravascular invasion in the } \\
\text { myometrium }\end{array}$ & & & \\
\hline & $\begin{array}{l}\text { Tumor marker: } \beta \text {-hCG } \\
50-80 \mathrm{mlU} / \mathrm{mL}\end{array}$ & & & & \\
\hline \multirow[t]{4}{*}{$3^{2}$} & Age: $46 \mathrm{yr}$ & Size: unknown & Myomectomy & Unknown & - \\
\hline & Gyn hx: para 1 & $\begin{array}{l}\text { Location: subserosal mass arising from the } \\
\text { posterior surface of the uterus }\end{array}$ & $\begin{array}{l}\text { Additional TAH, BSO, } \\
\text { and bilateral pelvic } \\
\text { lymphadenectomy }\end{array}$ & & \\
\hline & $\begin{array}{l}\text { Clinical sign: } \\
\text { vaginal bleeding }\end{array}$ & $\begin{array}{l}\text { Micro: } \\
\text { Adenomyoma with focal predominant endometrial } \\
\text { stroma and periglandular cuffs } \\
\text { Endometrial stromal cells in the periglandular cuffs } \\
\text { showing mild and focal moderate cytological } \\
\text { atypia with sparse mitotic figures, including an } \\
\text { occasional atypical form }\end{array}$ & & & \\
\hline & Tumor marker: unknown & & & & \\
\hline \multirow[t]{4}{*}{$4^{5}$} & Age: $38 \mathrm{yr}$ & Size: $1.5 \mathrm{~cm}$ & $\begin{array}{l}\text { Exploratory } \\
\text { laparotomy, } \\
\text { TAH, LSO, and } \\
\text { omentectomy }\end{array}$ & $\begin{array}{l}\text { Disease-free } \\
30 \text { mo after } \\
\text { treatment }\end{array}$ & $\begin{array}{l}\text { Heterologous element } \\
\text { (rhabdomyosarcoma) }\end{array}$ \\
\hline & Gyn hx: gravida 1, para 0 & Location: right cornual area & $\begin{array}{l}\text { Adjuvant cisplatin, } \\
\text { ifosfamide, and } \\
\text { mesna }\end{array}$ & & \\
\hline & $\begin{array}{l}\text { Clinical sign: chronic pelvic } \\
\text { pain and dysmenorrhea }\end{array}$ & $\begin{array}{l}\text { Micro: } \\
\text { Irregular glands with benign epithelium } \\
\text { surrounded by a hypercellular spindle cell } \\
\text { stroma showing rare mitoses, mild nuclear } \\
\text { hyperchromasia, and pleomorphism }\end{array}$ & $\begin{array}{l}5,500 \text { cGy to the } \\
\text { abdominal wall }\end{array}$ & & \\
\hline & $\begin{array}{l}\text { Tumor marker } \\
\text { CEA and AFP: normal } \\
\text { CA125: } 45 \mathrm{U} / \mathrm{mL}\end{array}$ & & & & \\
\hline \multirow[t]{3}{*}{$5^{10}$} & Age: $52 \mathrm{yr}$ & Size: uncheckable (no distinct mass formation) & $\begin{array}{l}\text { Radical hysterectomy } \\
\text { with BSO and } \\
\text { lymph node } \\
\text { dissection and } \\
\text { debulking of the } \\
\text { pelvic mass }\end{array}$ & Unknown & $\begin{array}{l}\text { Extrauterine pelvic } \\
\text { mass ( } 19 \mathrm{~cm} \text { in } \\
\text { diameter) diagnosed } \\
\text { as adenosarcoma with } \\
\text { rhabdomyosarcomatous } \\
\text { differentiation and } \\
\text { stromal overgrowth }\end{array}$ \\
\hline & Gyn hx: gravida 3, para 3 & Location: uterine fundus & & & \\
\hline & Peri-menopausal & $\begin{array}{l}\text { Micro: } \\
\text { Diffuse adenomyosis with focal stromal expansion, } \\
\text { consisting of a hypercellular proliferation of } \\
\text { moderately atypical spindle cells with mitotic } \\
\text { activity around benign endometrial glands and } \\
\text { infiltrating the anterior myometrium }\end{array}$ & & & \\
\hline
\end{tabular}


Table 1. Continued

\begin{tabular}{|c|c|c|c|c|c|}
\hline $\begin{array}{l}\text { Case No. } \\
\text { (ref No.) }\end{array}$ & Clinical feature & Pathology & Treatment & Outcome & Remarks \\
\hline & Clinical sign: none & & & & \\
\hline & $\begin{array}{l}\text { Tumor marker } \\
\text { CA125: } 258 \mathrm{U} / \mathrm{mL}\end{array}$ & & & & \\
\hline \multirow[t]{4}{*}{$6^{14}$} & Age: $53 \mathrm{yr}$ & Size: unknown & Unknown & Unknown & $\begin{array}{l}\text { Developed breast } \\
\text { carcinoma and received } \\
\text { adjuvant chemotherapy } \\
\text { including tamoxifen }\end{array}$ \\
\hline & Gyn hx: unknown & Location: unknown & & & \\
\hline & Clinical sign: unknown & $\begin{array}{l}\text { Micro: } \\
\text { Uterine adenosarcoma following } \\
\text { an adenomyoma }\end{array}$ & & & \\
\hline & Tumor marker: unknown & & & & \\
\hline \multirow[t]{4}{*}{7} & Age: $40 \mathrm{yr}$ & Size: $7.5 \mathrm{~cm}$ & $\begin{array}{l}\text { Laparoscopically } \\
\text { assisted TVH }\end{array}$ & $\begin{array}{l}\text { No evidence } \\
\text { of recurrence } \\
\text { to date }\end{array}$ & This case \\
\hline & Gyn hx: gravida 2, para 2 & Location: uterine fundus & Additional BSO & & \\
\hline & $\begin{array}{l}\text { Clinical sign: sudden-onset } \\
\text { suprapubic pain and initial } \\
\text { low back pain }\end{array}$ & $\begin{array}{l}\text { Micro: } \\
\text { Dilated glandular elements and abundant, } \\
\text { hypercellular stromal elements } \\
\text { Expansile growth within the myometrium with } \\
\text { extensive myometrial invasion and focal infiltration } \\
\text { with expansile margin into the subserosa } \\
\text { Focal involvement of adenomyosis }\end{array}$ & & & \\
\hline & $\begin{array}{l}\text { Tumor marker } \\
\text { CA125: 5,000 U/mL } \\
\text { CA19-9: } 39 \mathrm{U} / \mathrm{mL} \\
\text { B-hCG, AFP: normal }\end{array}$ & & & & \\
\hline
\end{tabular}

Gyn Hx, gynecological history; hCG, human chorionic gonadotropin; Micro, microscopic findings; TAH, total abdominal hysterectomy; BSO, bilateral salpingooophorectomy; LSO, left salpingo-oophorectomy; CEA, carcinoembryonic antigen; AFP, $\alpha$-fetoprotein; CA, carbohydrate antigen; TVH, total vaginal hysterectomy.

chromosomes 2, 8, 10, 13, 19, and $21 .{ }^{18}$ Finally, studies have also suggested that the use of tamoxifen may have a role in the pathogenesis of adenosarcoma. ${ }^{1,14}$

Several types of uterine tumors, including adenofibroma, adenosarcoma, and carcinosarcoma, consist of mixtures of epithelial and stromal components. ${ }^{13}$ Because they include large hypocellular areas and infrequent mitoses, adenosarcomas are difficult to histologically differentiate from adenofibromas, endometriosis and adenomyosis. Especially on a background of adenomyosis, a conclusive pathologic differential diagnosis may be more difficult, because florid adenomyosis can prevent an accurate initial diagnosis. In typical adenomyosis, the volume of the endometrial stromal component is low relative to the volume of smooth muscle. ${ }^{2}$ Moreover, although endometrial stromal cells have mitotic activity, they show no evidence of significant cytological atypia. ${ }^{2}$ Similarly, stromal mitoses of $\geq 2$ per $10 \mathrm{HPFs}$, marked stromal cellularity, and significant stromal cell atypia can differentiate Müllerian adenosarcoma from Müllerian adenofibroma. ${ }^{16}$ In one study, the diagnoses of eight adenomyomas were revised as adenofibroma, atypical polypoid adenomyoma, adenocarcinoma, and adenosarcoma. ${ }^{19}$ The adenofibroma contains variably cellular fibrous tissue in stroma,
Table 2. The 2009 FIGO staging system for uterine adenosarcoma

\begin{tabular}{ll}
\hline Stage & \multicolumn{1}{c}{ Definition } \\
\hline I & $\begin{array}{l}\text { Tumor limited to uterus } \\
\text { Tumor limited to endometrium/endocervix with no myometrial } \\
\text { invasion }\end{array}$ \\
IB & $\leq 50 \%$ myometrial invasion \\
IC & $>50 \%$ myometrial invasion \\
II & Tumor extension beyond the uterus, within the pelvis \\
IIA & Adnexal involvement \\
IIB & Involvement of other pelvic tissues \\
III & Tumor invasion of abdominal tissues (not just protruding into the \\
& abdomen) \\
IIIA & 1 site \\
IIIB & $>1$ site \\
IIIC & Metastasis to pelvic and/or para-aortic lymph nodes \\
IV & \\
IVA & Tumor invasion of bladder and/or rectum \\
IVB & Distant metastasis \\
\hline
\end{tabular}

FIGO, International Federation of Gynecology and Obstetrics.

but lacks the smooth muscle and endometrial stromal tissue present in adenomyoma. ${ }^{2}$ In adenosarcoma, the endometrial stromal tissue predominates, not the smooth muscle component, and the glands are no longer evenly distributed but are more widely 
separated due to stromal expansion. ${ }^{2}$ Smooth muscle may be found in the stroma of adenosarcomas, but it is rarely prominent. ${ }^{2}$ Typically, cambium layer is not found in adenomyoma, which is characteristic for adenosarcomas. ${ }^{2}$ Although mitotic activities in stroma have been reported in a few cases of adenomyomas, the stromal atypia is not found in these tumors. ${ }^{2}$ Finally, adenosarcoma may show myometrial and vascular invasion. ${ }^{2}$ Evidences that the tumor in our patient was a low-grade Müllerian adenosarcoma included an extensive expansile growth pattern of stromal and glandular tissue throughout the myometrium with involvement of the uterine serosal surface, the presence of epithelial metaplasia within the glandular components of the tissue, and frequent mitoses.

Müllerian adenosarcoma has been regarded as a low-grade tumor with a fair prognosis. Most tumors can be cured with surgery, but recurrence is associated with poor outcomes. ${ }^{7}$ Müllerian adenosarcomas rarely give rise to distant metastasis. The outcome of uterine adenosarcomas is associated with many factors, including the grade and mitotic activity of the stromal component; however, the presence of sarcomatous overgrowth and invasion into the myometrium, the key factors of the FIGO staging system, are the most important. ${ }^{2}$ Unlike most adenosarcomas, those comprising more than $25 \%$ of the sarcomatous component are considered high-grade. ${ }^{13}$ These tumors are more aggressive than most Müllerian adenosarcomas, which are usually of low malignant potential. ${ }^{16}$ One study found that $38 \%$ of patients had recurrent disease, with histologic sarcomatous overgrowth being a predictor of poor prognosis $(\mathrm{p}=.03){ }^{6}$ A second study reported recurrence in $36 \%$ of patients with adenosarcoma with myometrial invasion, and the risk of recurrence in the absence of myoinvasion was only $7 \%{ }^{20}$ Tumors that arise in the ovaries and extrauterine sites tend to have a higher recurrence rate, perhaps due to the lack of a physical barrier preventing spread within the pelvis and abdomen. ${ }^{1}$

Because adenosarcomas occasionally show an aggressive clinical behavior, despite benign or low-grade microscopic appearance, an aggressive therapeutic approach has been recommended. ${ }^{7}$ However, caution should be exercised, as it may lead to overtreatment of some patients. ${ }^{7}$ The current treatment of choice is hysterectomy and bilateral salpingo-oophorectomy; however, some patients have undergone selective myomectomies, with variable results. ${ }^{2,10,13}$ Tumors showing a pattern of sarcomatous overgrowth require more aggressive surgery. ${ }^{13}$ Imaging with PET-CT and MRI may be helpful for preoperative planning, monitoring the treatment response, and postoperative surveillance and restaging. ${ }^{13}$ Platin-based adjuvant chemotherapy and radiotherapy have been used to treat patients with aggressive prognostic factors, such as deep myometrial invasion and sarcomatous overgrowth., ${ }^{2,7}$
The lack of a staging system for uterine adenosarcoma led to development of the FIGO staging system for endometrial carcinomas. ${ }^{3}$ The new FIGO staging system for uterine adenosarcoma, published in 2009, is identical to that for endometrial stromal sarcoma ${ }^{9}$ (Table 2) and is an improvement on the earlier generic application of the 1988 FIGO staging system for endometrial cancer to adenosarcoma. ${ }^{8}$

Because of tumor involvement of the outer half of the myometrium, the tumor in our case would be staged as IC (deeply myoinvasive) according to the new FIGO staging system for uterine sarcomas. ${ }^{9}$ Stage IC tumors would normally be considered for adjuvant treatment. ${ }^{2}$ However, the FIGO staging applies to adenosarcomas that arise in the endometrium and invade into the myometrium. ${ }^{2}$ Thus, use of a staging system that does not consider adenosarcomas that arise ab initio within the myometrium, and are confined to this layer, would have resulted in overstaging of the adenosarcoma in our patient. ${ }^{2}$

To date, there are no specific staging guidelines for tumors arising from adenomyosis. In a series of case reports, two previous cases of adenosarcomas were reported to be problematic in staging. ${ }^{8}$ The first was a tumor that arose in the eutopic endometrium with involvement of underlying adenomyosis but without myometrial invasion. The second was a tumor located in an intramural adenomyoma with no evidences of a primary lesion in the eutopic endometrium. It was suggested that these tumors should be noted as adenosarcoma, intramural stage I am1 or am2, whether the involved adenomyosis/adenomyoma was located in the inner or outer half of the myometrium. Such a classification system would facilitate reliable data collection, allowing the formulation of an evidence-based staging system for these tumors. ${ }^{8}$

In conclusion, this report describes the clinical and pathologic findings of a rare extraendometrial, intramural adenosarcoma arising from adenomyosis without eutopic endometrial involvement in a 40-year-old woman. Malignant transformation of adenomyosis should be considered in the differential diagnosis of a huge solid and cystic uterine mass. To avoid overstaging and inappropriate treatment, it is important to recognize that adenosarcomas can, although rarely, arise from adenomyosis. Collection of additional data and prospective studies will provide a clearer understanding of the malignant transformation of adenomyosis and may provide more evidences for an upgraded staging system.

\section{Conflicts of Interest}

No potential conflict of interest relevant to this article was reported. 


\section{Acknowledgments}

This research was supported by Basic Science Research Program through the National Research Foundation of Korea (NRF) funded by the Ministry of Education (NRF-2017R1D1A1B03 036519).

\section{REFERENCES}

1. Pinto A, Howitt B. Uterine adenosarcoma. Arch Pathol Lab Med 2016; 140: 286-90.

2. Elshafie M, Rahimi S, Ganesan R, Hirschowitz L. Müllerian adenosarcoma arising in a subserosal adenomyoma. Int J Surg Pathol 2013; 21: 186-9.

3. McCluggage WG. Müllerian adenosarcoma of the female genital tract. Adv Anat Pathol 2010; 17: 122-9.

4. Raffaelli R, Piazzola E, Zanconato G, Fedele L. A rare case of extrauterine adenosarcoma arising in endometriosis of the rectovaginal septum. Fertil Steril 2004; 81: 1142-4.

5. Gollard R, Kosty M, Bordin G, Wax A, Lacey C. Two unusual presentations of mullerian adenosarcoma: case reports, literature review, and treatment considerations. Gynecol Oncol 1995; 59: 412-22.

6. Verschraegen CF, Vasuratna A, Edwards C, et al. Clinicopathologic analysis of Müllerian adenosarcoma: the M.D. Anderson Cancer Center experience. Oncol Rep 1998; 5: 939-44.

7. Liu L, Davidson S, Singh M. Müllerian adenosarcoma of vagina arising in persistent endometriosis: report of a case and review of the literature. Gynecol Oncol 2003; 90: 486-90.

8. Clarke BA, Mulligan AM, Irving JA, McCluggage WG, Oliva E. Müllerian adenosarcomas with unusual growth patterns: staging issues. Int J Gynecol Pathol 2011; 30: 340-7.

9. Prat J. FIGO staging for uterine sarcomas. Int J Gynaecol Obstet 2009; 104: 177-8.

10. Jha $P$, Ansari $C$, Coakley FV, et al. Case report: Imaging of Müllerian adenosarcoma arising in adenomyosis. Clin Radiol 2009; 64: 645-8.
11. Major FJ, Blessing JA, Silverberg SG, et al. Prognostic factors in earlystage uterine sarcoma: a Gynecologic Oncology Group study. Cancer 1993; 71(4 Suppl): 1702-9.

12. Abeler VM, Royne O, Thoresen S, Danielsen HE, Nesland JM, Kristensen GB. Uterine sarcomas in Norway: a histopathological and prognostic survey of a total population from 1970 to 2000 including 419 patients. Histopathology 2009; 54: 355-64.

13. Early HM, McGahan JP, Naderi S, Lamba R, Fananapazir G. Mullerian adenosarcoma: a malignant progression of adenomyosis? Pictorial review with multimodality imaging. J Ultrasound Med 2015; 34: 2109-13.

14. Bocklage T, Lee KR, Belinson JL. Uterine Müllerian adenosarcoma following adenomyoma in a woman on tamoxifen therapy. Gynecol Oncol 1992; 44: 104-9.

15. Oda Y, Nakanishi I, Tateiwa T. Intramural Müllerian adenosarcoma of the uterus with adenomyosis. Arch Pathol Lab Med 1984; 108: 798-801.

16. Clement PB, Scully RE. Müllerian adenosarcoma of the uterus: a clinicopathologic analysis of 100 cases with a review of the literature. Hum Pathol 1990; 21: 363-81.

17. Howitt BE, Sholl LM, Dal Cin P, et al. Targeted genomic analysis of Müllerian adenosarcoma. J Pathol 2015; 235: 37-49.

18. Chen Z, Hong B, Drozd-Borysiuk E, Coffin C, Albritton K. Molecular cytogenetic characterization of a case of Müllerian adenosarcoma. Cancer Genet Cytogenet 2004; 148: 129-32.

19. Gilks CB, Clement PB, Hart WR, Young RH. Uterine adenomyomas excluding atypical polypoid adenomyomas and adenomyomas of endocervical type: a clinicopathologic study of 30 cases of an underemphasized lesion that may cause diagnostic problems with brief consideration of adenomyomas of other female genital tract sites. Int J Gynecol Pathol 2000; 19: 195-205.

20. Gallardo A, Prat J. Müllerian adenosarcoma: a clinicopathologic and immunohistochemical study of 55 cases challenging the existence of adenofibroma. Am J Surg Pathol 2009; 33: 278-88. 